\title{
Physicians' interpersonal relationships and professional standing seen through the eyes of the general public in Croatia
}

This article was published in the following Dove Press journal:

Patient Preference and Adherence

25 August 2014

Number of times this article has been viewed

\author{
Marko Ćurkovićl \\ Milan Milošević ${ }^{2}$ \\ Ana Borovečki ${ }^{3}$ \\ Jadranka Mustajbegović ${ }^{2}$ \\ 'University Psychiatric Hospital \\ Vrapče, Zagreb, Croatia; ${ }^{2}$ Department \\ of Environmental and Occupational \\ Health, School of Public Health \\ "Andrija Štampar," University of \\ Zagreb, School of Medicine, Zagreb, \\ Croatia; ${ }^{3}$ Department of Social \\ Medicine and Organization of Health \\ Care, School of Public Health "Andrija \\ Štampar," University of Zagreb, School \\ of Medicine, Zagreb, Croatia
}

Correspondence: Marko Ćurković University Psychiatric Hospital Vrapče, Bolnička cesta 32, 10000 Zagreb, Croatia Tel +385 I 3780666

Fax +385 I 3483660

Email markocurak@gmail.com
Purpose: Medical professionalism, as a cornerstone of medicine's social contract with society, demands physicians adhere to high professional standards while placing public interest ahead of self-interest. This study's objective was to investigate perceptions of the basic elements of medical professionalism related to physicians' interpersonal relationships and their professional standing in the view of the broader public.

Methods: A field survey was conducted using an independently created questionnaire on a nationally representative three-stage probabilistic sample of 1,008 Croatian citizens. By including weights, the sample became nationally representative in terms of sex, age, education, and regional representation. The survey was carried out from April 17 to May 13, 2012.

Results: The Croatian public recognizes the importance of collaboration among physicians, but their everyday experiences tell a different story, in which almost half of the respondents evaluated physicians' collaboration as being mediocre, poor, or nonexistent. The perception of physicians' priorities and their primary interests, where every sixth respondent believes physicians always or almost always puts their own interest in front of that of the patients, as well as the perception of their inadequate adherence to professional standards, is indicative of a disillusioned stance of the public toward the medical profession in Croatia.

Conclusion: This research offered insight into findings that can have a profound and long-lasting effect on a health care delivery process if they are not further analyzed and rectified.

Keywords: medical professionalism, professional standing, questionnaire, public opinion, Croatia

\section{Introduction}

There is an emerging need for good physician-physician relationships and adherence to high professional standards in contemporary medical practice with regard to the evergrowing complexities of modern medicine and society. ${ }^{1-4}$ Professionalism demands that professionals promote good interpersonal relationships and at the same time place public interest ahead of self-interest, taking into account both individual and public moral and fiduciary obligations when dealing with an individual patient. ${ }^{5-8}$

On July 1, 2013, Croatia became the 28th member state of the European Union. Adding to the economic and legislative challenges facing Croatian society are other hidden challenges Croatian citizens face every day. The Croatian health care system is still in transition. An all-encompassing social health care insurance model is often confronted with a tendency to turn it into a public-private mix. ${ }^{9,10}$ Such tendencies can put a lot of strain on physician-physician and physician-patient relationships. The physician-patient relationship has often been the focus of different studies performed in Croatia. ${ }^{11}$ However, to date, the physician-physician relationship has 
not been examined in Croatia or a broader region, or in a transitional (post-communist) context in general. That is why we recently started to explore physician-physician relationships as a part of a larger scientific project. This article presents a study on the general public's perceptions of physician-physician relationships and their professional standing in Croatia. We used general public perspective, keeping in mind the most recent shift from the physicians' perspective of defined medical professionalism toward a public (patient)-centered perspective that is recognized in the construct of social (moral) contract, as well as in the concept of patient centered care..$^{5-8}$

\section{Methods}

A field survey was conducted using an independently created questionnaire on a nationally representative three-stage probabilistic sample of 1,008 participants. Of a total of 3,475 persons who participated in the survey, 1,008 completed the questionnaire (response rate, 29\%). Replies of 21 minors were excluded, and weighted statistical analysis was performed. By including weights, the sample became nationally representative in terms of sex, age, education, and regional representation. The average age of the respondents was $42.0 \pm 14.5$ years. Women made up $52.5 \%$ of the total sample. Sampling methods used in the research included stratified random sampling. At the time of conducting the research, the available data from the 2001 census were used as a data source for stratifying. According to the proportional share of the population, the required number of respondents in each county was predefined. Settlements (cities, villages) were randomly selected, taking into account the rural-urban distribution in each county. The place of residence in each settlement was randomly selected by the random walk method, in which randomly selected surveyors entered every third household on their right side. In each household, the last birthday method was used as a selection criterion. Replying to the questionnaire was voluntary and was not rewarded; the anonymity of the participants was ensured. The survey was carried out from April 17 to May 13, 2012.

A short questionnaire was created using a focus group discussion as a part of a larger qualitative study. Physicians, assistant medical faculty, psychologists, statisticians, and epidemiologists took part in creating the questionnaire. The final questionnaire consisted of 10 questions. Demographical data (sex, age, educational level, personal income level [expressed in Kuna per month], and place of residence) were also gathered. The study was approved by the University of Zagreb School of Medicine Ethics Committee.

Statistical analysis of the results was performed using SPSS Statistics, version 19.0.0.1 (IBM Corporation, Armonk, NY, USA). The differences between category variables were tested using the chi-square test for nominal or dichotomous variables. For variables measured by ordinal (continuous) scales, we used independent $t$-test and one-way analysis of variance, as the distribution of variables was shown to be appropriate for using parametric tests. Results from ordinal scales (ranging from a minimum of 1 to a maximum of 5) are shown as mean values and standard deviation, where higher values express a higher rate of the respondents' agreement with the investigated phenomenon. The significance level was set at $P<0.05$.

\section{Results}

Table 1 shows the distribution of answers among the study participants. The distribution of answers according to sex, age, income level, and level of education is presented in Table 2 and Table 3.

When asked about physician-physician interactions they observed during the health care delivery process, almost half of the respondents $(48.7 \%)$ considered the collaboration among physicians to be mediocre, poor, or nonexistent. However, the vast majority of the respondents $(94.1 \%)$ consider collaboration and communication to be important or very important for adequate provision of health care. Older respondents evaluated their experience with physician-physician interactions as highly positive, whereas the respondents with a higher level of education expected a better and higher level of quality regarding physician-physician interactions. One in six of the respondents $(16.2 \%)$ experienced physicians' comments on their fellow colleagues' work, of which most were negative critiques $(56.2 \%)$. Of the respondents, $4.2 \%$ witnessed a conflict between physicians, with verbal conflict of a professional nature being the most common type (57.2\%). Humiliation, discrimination, or intimidation of physicians by their fellow colleagues was witnessed by $3 \%$ of the respondents. Younger respondents, respondents with a higher level of education, and respondents in a higher income category were more sensitive to the aforementioned issues. Male respondents were more susceptible to the issue of unprofessional and unethical behavior among fellow colleagues than female respondents.

We also examined some highlights concerning experiences and expectations of the general public about the 
Table I Distribution of answers among study participants

Questions and answers

Number (\%)

I. What is your experience of collaboration among Croatian physicians?

None

$72(7.8)$

Poor

$95(10.3)$

Average

$284(30.6)$

Good

$397(42.8)$

Excellent

79 (8.5)

2. In your opinion, please rate the importance of collaboration and communication among physicians for an efficient and adequate provision of health care

Not at all

$3(0.4)$

Not important

$6(0.6)$

Neither yes nor no

45 (4.9)

Important

$373(40.2)$

Very important

3. Do you think that physicians put their own interest in front of their patients' health?

Never

I0I (10.9)

No in most cases

$350(37.7)$

Sometimes yes, sometimes no

$313(33.7)$

Yes in most cases

I31 (14.1)

Yes, always

35 (3.7)

4. Have you ever participated in or witnessed bribery and corruption in the health care system? Yes

$147(15.8)$

No

$781(84.2)$

5. Have you had to use some personal connections to be treated adequately?

Yes

$255(27.5)$

No

673 (72.5)

6. In your opinion, are physicians adequately paid for their work?

Yes

No*

$438(47.2)$

$490(52.8)$

Overpaid

70 (14.4)

Underpaid

$420(85.6)$

7. Do physicians do their work conscientiously and responsibly?

Not at all

$4(0.4)$

Mostly no

$52(5.6)$

Sometimes yes, sometimes no

$338(36.4)$

Yes, in most of cases

$422(45.4)$

Yes, always

I 12 (12.1)

8. Have you ever experienced physicians commenting on their fellow colleagues' work?

Yes*

I5I (16.2)

No

$777(83.8)$

What was the content of the comments?

Criticism

$85(56.2)$

Vilification

$14(9.6)$

Positive critics

$35(23.3)$

Praise

$14(9.0)$

Something else

$3(2.0)$

9. Have you ever witnessed a conflict between physicians?

Yes*

39 (4.2)

No

What kind of conflict was it?

Verbal conflict of a private nature

$12(31.6)$

Verbal conflict of a professional nature

$23(57.2)$

Sexual discrimination

I (3.1)

Vilification or humiliation

$3(8.1)$

10. Have you ever witnessed a physician being a victim of unprofessional or unethical behavior

by their fellow colleague?

Yes*

$28(3.0)$

No

$900(97.0)$

(Continued) 
Table I (Continued)

\begin{tabular}{lc}
\hline Questions and answers & Number (\%) \\
\hline This behavior consisted of & $8(28.1)$ \\
$\quad$ Vilification and humiliation & $14(49.3)$ \\
Inappropriate jokes & $3(9.6)$ \\
Discrimination & $3(9.7)$ \\
Intimidation & \\
\hline
\end{tabular}

Note: *Elaborated in following subquestion.

everyday work of physicians. One in six of the respondents $(17.8 \%)$ believes physicians always or almost always put their own interest in front of their patients' health, whereas one third (33.7\%) consider that sometimes they do and sometimes they do not. This was most prominent among female respondents. In addition, $57.5 \%$ of the respondents believe that physicians do their work conscientiously and responsibly in most cases or always. This was most noticeable among respondents older than 65 years. Half of the respondents (52.8\%) consider physicians to be inadequately paid for their work, with the majority of those (85.6\%) being of the opinion that physicians are underpaid. Younger respondents and female respondents were more prone to consider physicians' salaries to be adequate, whereas the respondents within the category of college and higher education were of the opinion that physicians' salaries were inadequate. Roughly a sixth (15.8\%) of all respondents were participants in or witnesses of bribe and corruption in the health care system, and more than a quarter (27.5\%) had to use personal connections to be treated adequately. These findings had positive correlation with the age of the respondents that was most noticeable among respondents older than 65 years.

\section{Discussion}

Our study pointed out the existence of patterns of lessthan-collegial behavior among physicians in Croatia. The main problems observed were poor communication and collaboration. Medical practice requires teamwork, good communication practices, and good quality of collaboration, which is a prerequisite for an adequate and quality health care delivery process. Although not as commonly noted, conflicts and behavior that included patterns of mobbing practices (humiliation, discrimination, or intimidation) were also observed. According to Davenport et al, ${ }^{12}$ mobbing is typically found in work environments that have poorly organized production and/or working methods and inadequate or inattentive management; mobbing victims are usually "exceptional individuals who demonstrated intelligence, competence, creativity, integrity, accomplishment and dedication." $" 12$
These observed patterns of physicians' behaviors can create a lot of problems in a modern medical setting, which stresses the importance of an intense and efficient everyday inter- and intraprofessional collaboration. Physicians are health team leaders and have a strong obligation to demonstrate positive professional behavior as members of high standing in society. ${ }^{1-3,6,8}$ There is extensive evidence, according to the scientific literature, that these poor interpersonal relationships and other "lapses in professionalism" can have a profound effect on all aspects of the health care provision process and its outcomes. ${ }^{13,14}$

Our study also investigated current public perception of physicians' priorities and interests. One in six of our respondents believed that physicians always or almost always put their own interest before their patients' health. The survey yielded data indicative of a disillusioned stance of the public toward the medical profession. This is especially alarming if we consider that the need for public trust is the very basis of successful treatment and demands that professionals place public interest ahead of self-interest. However, more than half of our respondents believe physicians do their work conscientiously and responsibly in most cases or always. When it comes to physicians' salaries, as a certain indicator of professional standing, somewhat over half of our respondents were of the opinion that physicians should receive higher financial incentives for their work.

Our respondents report that in more than $15 \%$ of cases, they were participants or witnesses of informal payments (bribe given to physicians for their services), and more than $25 \%$ of them had used personal connections to receive adequate treatment. These findings are comparable to similar findings from studies conducted by civil society organizations, government institutions, and other researchers in our country., ${ }^{9,15,16}$ Corruption in Croatian health care is neither endemic nor sector-specific and represents an issue embedded in our communities' culture. ${ }^{16}$ The majority of the respondents who reported such behavior were those who, because of their age, are using health care services more than others (respondents older than 65 years). Let us not forget that elderly people are considered 


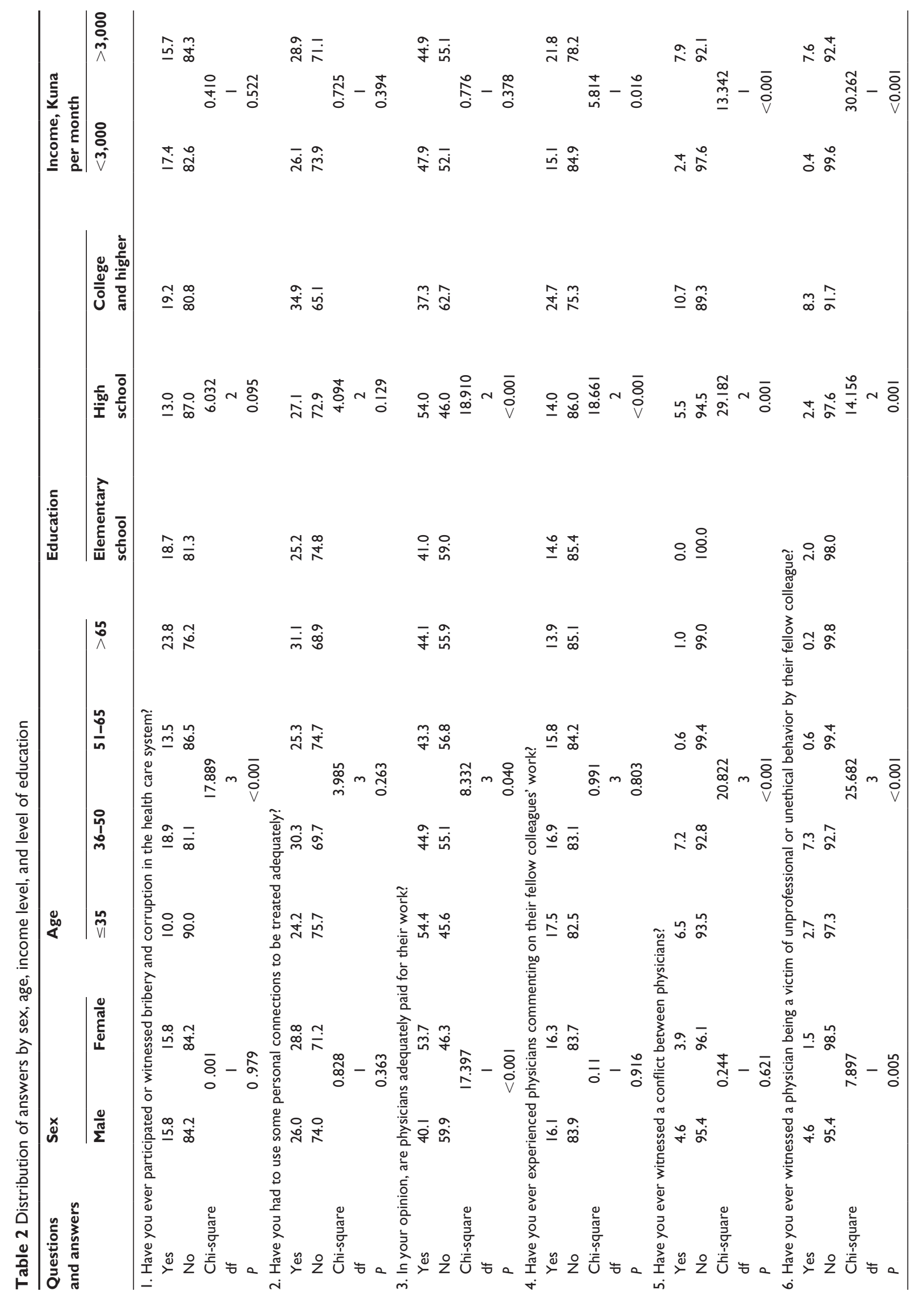




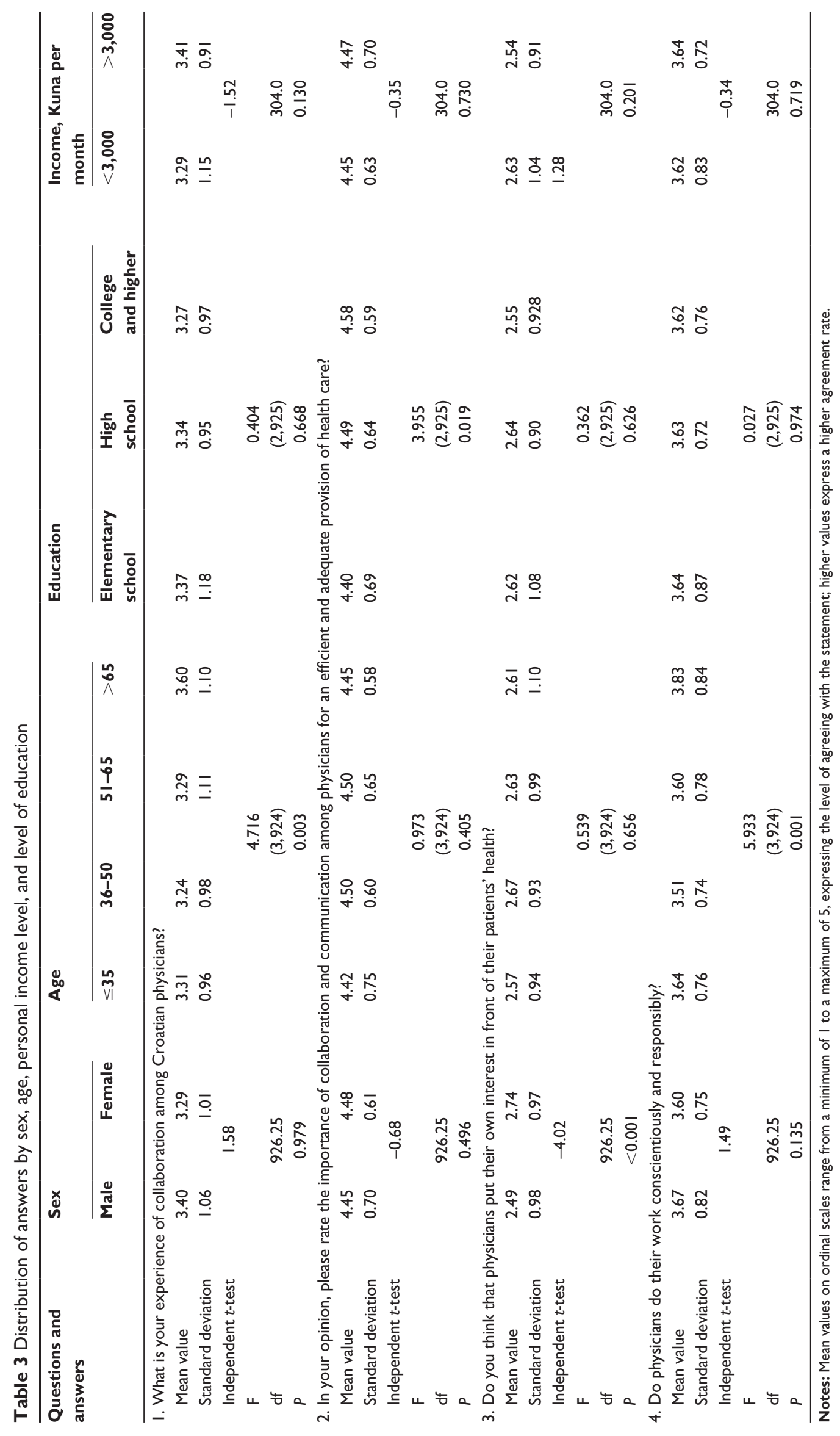


to be a vulnerable social group, and in Croatia, the majority of people older than 65 years are retired; in a lower-income group, some of them are even stricken by poverty. ${ }^{17,18}$ As we move up through educational categories, a growing tendency among percentages of reporting of the use of personal connection among more educated individuals can be seen. Although these findings did not reach a level of statistical significance, it seems the respondents with a higher level of education exhibited this kind of behavior more often, in accordance with their position of power and social connections at their disposal.

The response rate of $29 \%$, compared with an average response rate of $53 \%$ in the United States for face-to-face surveys, could be a limitation to our study. ${ }^{19}$ An additional limitation is that characteristics of persons who refused to participate in the study were not collected, and as a result, nonresponse analysis was not performed.

\section{Conclusion}

This research, as a first part of a larger project, offers a glimpse into the public's view on physician-physician relationships and into certain aspects of professional physician behavior in a transitional society that could have profound and long-lasting effects on the health care delivery process if not properly analyzed and rectified. Further research is needed to elucidate our findings. Our future intention is to investigate medical professionalism and physicians' professional interpersonal relationships, taking into account the view of all important stakeholders and ultimately elaborating possible strategies and interventions for its improvement, as well as providing proof of an argument for the development of a medical professionalism curriculum.

\section{Acknowledgments}

This research was funded by scientific research project under the patronage of the Croatian Ministry of Science, Education and Sports ("The effect of organization on the quality and effectiveness of health care," 108-1081871-91, and "Occupational health and a healthy environment," 108-1080316-0300).

We thank Andro Košec, MD, and Danijela Ćurković, $\mathrm{MD}$, for assisting in study design and manuscript review.

\section{Author contributions}

MĆ performed the study design, data analysis, interpretation of results, manuscript preparation, manuscript editing, and manuscript review. MM contributed to study design, data analysis, interpretation of results, and manuscript editing. $\mathrm{AB}$ performed study design, coordination of research, interpretation of results, manuscript preparation, manuscript editing, and manuscript review. JM participated in the study design, interpretation of results, manuscript editing, and manuscript review. All authors approved the final version of the manuscript.

\section{Disclosure}

The authors report no conflicts of interest in this work.

\section{References}

1. Swick HM. Toward a normative definition of medical professionalism. Acad Med. 2000;75(6):612-616.

2. Brennan TA. Physicians' professional responsibility to improve the quality of care. Acad Med. 2002;77(10):973-980.

3. Lesser CS, Lucey CR, Egener B, Braddock CH III, Linas SL, Levinson W. A behavioral and systems view of professionalism. JAMA. 2010; 304(24):2732-2737.

4. Hafferty FW, Castellani B. The increasing complexities of professionalism. Acad Med. 2010;85(2):288-301.

5. Wynia MK, Latham SR, Kao AC, Berg JW, Emanuel LL. Medical professionalism in society. $N$ Engl J Med. 1999;341(21): 1612-1616.

6. Cruess RL, Cruess SR. Expectations and obligations: professionalism and medicine's social contract with society. Perspect Biol Med. 2008;51(4):579-598.

7. Royal College of Physicians. Doctors in society: medical professionalism in a changing world. Report of a Working Party of the Royal College of Physicians of London. London: RCP; 2005.

8. Gruen RL, Pearson SD, Brennan TA. Physician-citizens - public roles and professional obligations. JAMA. 2004;291(1):94-98.

9. Voncina L, Jemiai N, Merkur S, et al. Croatia: health system review. Health Syst Trans. 2006;8:1-108.

10. Mastilica M, Kusec S. Croatian healthcare system in transition, from the perspective of users. BMJ. 2005;331(7510):223-226.

11. Vučemilo L, Ćurković M, Milošević M, Mustajbegović J, Borovečki A. Are physician-patient communication practices slowly changing in Croatia? - a cross-sectional questionnaire study. Croat Med J. 2013; 54(2):185-191.

12. Davenport N, Schwartz RD, Elliott GP. Mobbing: Emotional Abuse in the American Workplace. Ames, IA: Civil Society Publishing; 1999.

13. Leape LL, Shore MF, Dienstag JL, et al. Perspective: a culture of respect, part 1: the nature and causes of disrespectful behavior by physicians Acad Med. 2012;87(7):845-852.

14. van Mook WN, Gorter SL, De Grave WS, et al. Bad apples spoil the barrel: Addressing unprofessional behaviour. Med Teach. 2010; 32(11):891-898

15. Radin D, Džakula A, Benković V. Health care issues in Croatian elections 2005-2010: series of public opinion surveys. Croat Med J. 2011;52(5):585-592.

16. Bisogno E. Office on Drugs and Crime. Corruption in Croatia: Bribery as Experienced by the Population. UNODC; 2011:1-61.

17. The Croatian Bureau of Statistics. Pokazatelji Siromaštva U 2011. Konačni rezultati [Poverty Indicators 2011 - Final Results]. Zagreb, Croatia. Available from: http://www.dzs.hr/Hrv_Eng/ publication/2012/14-01-03_01_2012.htm. Accessed March 31, 2014. Croatian.

18. World Bank Croatia: living standards assesment. 1st vol. Promoting Social Inclusion and Regional Equity. Washington, DC: World Bank; 2006.

19. Galešić M. Utjecaj dužine upitnika na anketni odaziv. [Effect of questionnaire length on survey response rate]. Društvena Istraživanja. 2003; 12:807-824. Croatian. 


\section{Publish your work in this journal}

Patient Preference and Adherence is an international, peer-reviewed, open access journal that focuses on the growing importance of patient preference and adherence throughout the therapeutic continuum. Patient satisfaction, acceptability, quality of life, compliance, persistence and their role in developing new therapeutic modalities and compounds to optimize

clinical outcomes for existing disease states are major areas of interest for the journal. This journal has been accepted for indexing on PubMed Central. The manuscript management system is completely online and includes a very quick and fair peer-review system, which is all easy to use. Visit http://www. dovepress.com/testimonials.php to read real quotes from published authors.

Submit your manuscript here: http://www.dovepress.com/patient-preference-and-adherence-journal 